\title{
A inserção da lógica de mercado no campo cultural: a relação entre as instituições bancárias e a cultura em Recife
}

\section{The Insertion of the Logic of the Market in Cultural Field: the Relation between Banking Institutions and Culture in Recife}

\author{
Myrna Sueli da Silva Lorêto ${ }^{1}$ \\ Flávia Lopes Pacheco ${ }^{2}$
}

\begin{abstract}
Resumo
Ao se falar de cultura pernambucana, percebe-se que alguns grupos responsáveis por manifestações tradicionais estão encontrando dificuldades em permanecer realizando essas atividades culturais. Este fato decorre, entre outros motivos, devido à reforma do Estado que tende, a cada dia que passa, a diminuir os investimentos diretos em cultura, fazendo-o por meio de leis de incentivo à cultura e renúncia fiscal. É nesse contexto que as instituições bancárias perceberam uma nova fatia do mercado a atingir: o setor cultural. A fim de obterem legitimidade perante a comunidade da qual fazem parte, os bancos começam a se utilizar dos mecanismos governamentais, como as leis de incentivo à cultura, para conseguirem isenção de impostos ao financiarem projetos culturais e, ao mesmo tempo, alcançarem visibilidade junto ḋ mídia enquanto organizações socialmente responsáveis. Assim, propomo-nos a discutir de que modo está configurado o campo cultural que se formou a partir das ações de financiamento das instituições bancárias em Recife. Para isso, tomamos como base a Teoria Institucional, pois ela destaca aspectos como: o ambiente onde essas organizações estão inseridas e a noção de campo.
\end{abstract}

Palavras-chave: Cultura, Campo, Teoria Institucional, Instituições Financeiras

\begin{abstract}
When talking about culture in Pernambuco, it's possible to perceive that some of the groups responsible for traditional manifestations are having difficulties in carrying these cultural activities through. One of the reasons for this is the fact that the State tends to diminish the direct investments in the cultural area by means of cultural incentive laws and fiscal resignation. It is in this context that the banking institutions had perceived a new slice of the market to reach the cultural sector. In order to get legitimacy from the community where they operate, banks start to make use of governmental mechanisms such as cultural incentive laws aiming to obtain tax exemption when financing cultural projects and to achieve visibility in the media as socially responsible organizations. Thus, we propose to analyze the configuration of the cultural field in Recife based on Institutional Theory's notions such as environment and organiational field.
\end{abstract}

Keywords: Culture, Field, Institutional Theory, Banking Institutions

\footnotetext{
${ }^{1}$ Mestra em Administração pelo Programa de Pós-Graduação da Universidade Federal de Pernambuco. Pesquisadora do Observatório da Realidade Organizacional. Endereço: Av. Prof. Moraes Rêgo, 1235 - Cidade Universitária, Recife - Pernambuco - Brasil - CEP: 50670-901 E.Mail : myrnaloreto@gmail.com

${ }^{2}$ Doutoranda em Administração e pesquisadora do Observatório da Realidade Organizacional/PROPAD /UFPE. Endereço - Av. Prof. Moraes Rêgo, 1235 - Cidade Universitária, Recife - Pernambuco - CEP: 50670-901. Brasil - E-Mail : flavialpacheco@yahoo.com.br

Artigo recebido em outubro de 2006 e aceito para publicação em dezembro de 2006
} 


\section{Introdução}

Pernambuco é um estado conhecido por sua diversidade cultural, seja na música, com o frevo e o maracatu, seja pelos seus teatros e museus, como também por ser a terra natal de personalidades de destaque nessa área. Quando falamos de cultura pernambucana, percebe-se que alguns grupos responsáveis por manifestações culturais tradicionais têm encontrado dificuldade em manter suas atividades. Entre outros motivos, isso decorre da reforma do Estado, que vem reduzindo os investimentos diretos em cultura, investimentos esses que passam a ser feitos através de leis de incentivo e da renúncia fiscal.

O final da década de 1980 deixou-nos como marco uma lógica de ação baseada no diagnóstico de que era impossível manter o perfil estrutural dos modelos estatais vigentes, dado que o ambiente é altamente dinâmico, desterritorializado e repleto de riscos imprevisíveis. Foi determinado que o Estado só tinha um caminho: converter-se, para ter condições de auxiliar o desenvolvimento econômico e proteger os cidadãos das desigualdades que surgissem. Com isso, os países latino-americanos, inclusive o Brasil, passaram a aceitar esse "pensamento único" ditado pelos países centrais e começaram a aderir a práticas reformadoras, fortemente centradas na diminuição do Estado, e à conseqüente valorização do mercado. Assim, percebemos o surgimento de uma ação pública que, a cada dia, tende a diminuir os investimentos diretos em ações sociais, passando-os para as mãos das empresas e da sociedade, pretendendo cumprir apenas uma função reguladora.

É nesse contexto que as instituições bancárias perceberam uma nova fatia do mercado a atingir: o setor cultural. A fim de obterem legitimidade perante a comunidade da qual fazem parte, os bancos começam a se utilizar dos mecanismos governamentais, como as leis de incentivo à cultura, para conseguirem isenção de impostos ao financiarem projetos culturais e, ao mesmo tempo, alcançarem visibilidade junto à mídia como organizações socialmente responsáveis. Consideramos que um dos setores que mais sofrem com isso é o setor cultural, pois o Brasil, ao adotar as práticas econômicas baseadas no pensamento neoliberal, passa a implementar políticas culturais pautadas pelo "liberalismo cultural". Essas políticas não defendem modelos únicos de representação simbólica, assim como entendem que não é dever do Estado promover cultura e oferecer opções culturais para a população. Dessa forma, o apoio à cultura passa a depender mais da iniciativa privada, o que acaba por enquadrar a cultura nas leis de mercado. Entende-se, nesse caso, que a cultura deve ser uma atividade lucrativa a tal ponto que seja possível sustentar-se. Embora essa seja uma tendência, o Estado ainda é o principal financiador das organizações culturais pernambucanas.

Essa é a preocupação central que norteia este estudo. Pois, após realizar uma pesquisa empírica para uma dissertação de mestrado, que tinha como objetivo analisar a atuação das instituições bancárias no setor cultural em Recife, ficou clara a intencionalidade das suas ações e a forma como o campo passa a ser configurado a partir da influência de tais entidades. Assim, propomo-nos a discutir de que modo está configurado o campo cultural que se formou a partir das ações de financiamento das instituições bancárias em Recife. Para isso, tomamos como base a teoria institucional, pois ela destaca aspectos como o ambiente onde essas organizações estão inseridas e a noção de campo.

A cidade de Recife foi escolhida, antes de tudo, por ser o local em que as pesquisadoras vivem e, além disso, pela sua rica diversidade cultural. Por fazermos parte de um grupo de pesquisa que vem continuamente desenvolvendo trabalhos no campo da cultura pernambucana, partimos de uma preocupação, presente na maioria dos estudos desenvolvidos, que está fundada nas dificuldades encontradas por alguns grupos responsáveis pela manutenção das manifestações artísticas tradicionais. Nessas pesquisas, fica claro que o afastamento do Estado da função de agente de financiamento direto vem pressionando as organizações culturais a adotarem práticas condicionadas por regras de eficiência e competitividade, ou seja, pelos valores da lógica de mercado.

As questões principais que nortearam a elaboração desse estudo foram: "Por que as instituições bancárias resolveram investir em cultura?" e, posteriormente, "Como esse financiamento se reflete na configuração do campo cultural recifense?". Com o intuito de respondê-las, percebemos na teoria institucional um rico arcabouço capaz de levantar uma série de apontamentos que nos ajudaram a compreender melhor o objeto em estudo. 


\section{Teoria institucional}

A teoria institucional surgiu como uma alternativa às abordagens tradicionais que enfatizavam apenas os aspectos racionais relacionados à eficiência e à eficácia das organizações. Assim, ela veio demonstrar que as interações simbólicas também influenciam um processo de tomada de decisão, de forma que valores e crenças compartilhadas alcançam uma importância peculiar em detrimento da razão. De acordo com essa teoria, aspectos importantes a serem mencionados são as questões de ambiente e a noção de campo organizacional.

De acordo com Perrow (1990) a ênfase no ambiente é a principal contribuição da teoria institucional. As organizações estão inseridas em um ambiente constituído por regras, crenças e valores que são criados e consolidados por meio da interação social. As organizações são influenciadas por dois tipos de ambientes: o técnico e o institucional (MEYER; SCOTT, 1983). Conforme esses autores, as organizações são influenciadas por dois tipos de ambientes: o técnico e o institucional. A racionalidade do primeiro consiste no fato das organizações atuarem de forma mais eficiente, enquanto a do ambiente institucional foca a legitimidade. Assim, o ambiente institucional é formado pela criação de regras e valores socialmente aceitos, aos quais as organizações deverão se adequar se pretendem receber suporte e legitimidade do ambiente, enquanto o ambiente técnico envolve tecnologias complexas e trocas de produtos onde o mercado recompensa as organizações pelo controle eficiente e eficaz do seu processo de trabalho.

Machado-da-Silva e Fonseca (1996, p.103) definem que:

os ambientes técnicos [...] são aqueles cuja dinâmica de funcionamento desencadeia-se por meio da troca de bens ou serviços, de modo que as organizações que neles se incluem são avaliadas pelo processamento tecnicamente eficiente do trabalho [...]. Os ambientes institucionais caracterizam-se, por sua vez, pela elaboração e difusão de regras e procedimentos, que proporcionam às organizações legitimidade e suporte contextual.

É importante salientar que os ambientes técnico e institucional não são mutuamente excludentes (CARVALHO; VIEIRA; LOPES, 1998; VIEIRA; MISOCZKY, 2003). A distinção entre eles não implica dicotomia, pois essas categorias representam um continuum ao longo do qual se situam diferentes pressões e requisitos. Algumas organizações são mais reguladas pelo retorno que dá ao ambiente quanto à sua efetividade, como, por exemplo, as indústrias em geral. Outras organizações necessitam obter legitimidade do ambiente para realizarem as suas atividades. Nessa situação se encontram as universidades e igrejas, em relação às quais o reconhecimento vem através dos valores que estão inseridos.

Scott e Meyer (2001) realizaram um estudo onde relatam justamente o grau de influência dos dois tipos de ambientes nas organizações. O quadro 1 exemplifica melhor os setores que sofrem pressões dos dois tipos de ambiente enfocados. 
Quadro 1

Pressões dos ambientes técnico e institucional

\begin{tabular}{|c|c|c|c|}
\hline & & Ambientes institucion & 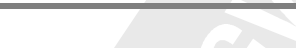 \\
\hline & & Mais forte & Mais fraco \\
\hline & & serviços públicos & \\
\hline & Mais forte & bancos & manufatura em geral \\
\hline & & hospitais & \\
\hline Ambientes técnicos & & clínicas de saúde mental & \\
\hline & & escolas & \\
\hline & & agências legais & \\
\hline & & igrejas & \\
\hline
\end{tabular}

Fonte: Scott e Meyer (2001, p.171)

De acordo com os autores, existem setores que sofrem pressões, no mesmo nível de intensidade, do ambiente técnico e institucional, como, por exemplo, os bancos. Estes têm de ser eficientes, pois sem lucro, não haverá clientes e, ao mesmo tempo, obter legitimidade para continuarem reconhecidos no campo em que atuam, mostrando aos seus clientes que aquela instituição bancária é sólida e que os seus investimentos estão em local seguro.

Assim, a partir do que foi visto anteriormente, as instituições bancárias começam a se preocupar também com questões relacionadas ao seu ambiente institucional, buscando atingir legitimidade perante seu público, partindo para ações voltadas ao financiamento de ações culturais. Esse parece ser um dos fatores que motivam a inserção dos bancos num campo que lhe é estranho. Além disso, não se pode deixar de considerar as pressões ambientais ocasionadas pelo novo contexto mundial. As empresas começam a interferir em áreas que eram de responsabilidade exclusiva do Estado, pois percebem que, ao não investirem em, não obterão vantagem competitiva sobre as demais.

Há também aqueles que são mais pressionados pelo ambiente técnico do que pelo institucional. São aqueles regidos pelo mercado, ou seja, as indústrias em geral. Quanto às igrejas e as universidades, estas sofrem pressões inversas, pois são mais pressionadas pelo ambiente institucional.

Ainda em relação ao trabalho de Scott e Meyer (2001) é importante ressaltar que o quadro apresentado pelos autores retrata o cenário encontrado diante das variáveis ambientais que influenciavam o seu objeto de estudo. Isso implica dizer que outra disposição das organizações pode ser encontrada diante das pressões ambientais.

De acordo com estudos que estão sendo elaborados no Brasil, os clubes desportivos estão passando por um processo de regulação, o que faz com que sofram uma pressão maior do ambiente técnico (MAGALHÃES FILHO, 2003), diferentemente do que ocorria antes, quando as questões do ambiente institucional recebiam maior atenção, assim como ocorre com as organizações culturais (JÓFILI; DIAS; CARVALHO, 2003; MADEIRO; CARVALHO, 2003; VIEIRA; CARVALHO, 2003). Entretanto, é necessário enfatizar que: 
Podem ser encontradas forças e pressões exercidas pelos dois modelos de ambiente, em diferentes proporções, em todos os tipos de organizações, o que indica a existência não de dicotomias, senão que de um contínuo onde podem existir todo tipo de combinações. (CARVALHO; VIEIRA; LOPES, 1998, p.8).

Além do ambiente, gostaríamos de ressaltar a noção de campo organizacional, que seria o espaço onde uma ou mais organizações interagem. Para DiMaggio e Powell (2001a, p.106), o campo organizacional é formado por "aquelas organizações que, em conjunto, constituem uma área reconhecida da vida institucional”; ou seja, o campo é formado por diversos atores sociais - como agências reguladoras, concorrentes e representantes governamentais, entre outros - cujo objetivo é ter poder dentro do campo organizacional, estabelecendo assim uma relação de dependência (ALDRICH apud LEÃO JR. et al, 2001).

O estudo sobre o tema campos organizacionais é pouco explorado. Uma das publicações mais conhecidas é a pesquisa realizada por Paul DiMaggio entre 1920 e 1940 com os museus de arte dos Estados Unidos. No Brasil, este é ainda um tema recente na área dos estudos organizacionais, mas pode-se perceber um número crescente de pesquisas a esse respeito nas publicações mais atuais (CARVALHO; VIEIRA e LOPES, 2001; LEÃO JR, 2001, 2003; LOPES, 1999; MISOCZKY, 2001; ROMANO; VASCONCELLOS, 2003; VIEIRA; MISOCZKY, 2003).

DiMaggio (2001) ressalta a importância dos estudos do campo para a abordagem institucional por dois motivos. O primeiro está relacionado ao fato dessa teoria se concentrar em processos de influência mútua entre as organizações, ou seja, as fronteiras do campo. Essas fronteiras, tal como são percebidas pelos participantes do campo, podem influenciar a forma como esses atores organizacionais se comparam aos demais. $\mathrm{O}$ segundo motivo aborda o fato da teoria institucional prestar particular atenção no modo como as agências governamentais e as associações profissionais que se encontram fora da indústria, porém dentro de um setor ou campo, influenciam ou limitam as organizações que produzem bens ou serviços dentro da indústria. O Estado e as agências reguladoras são os principais atores que colaboram para a configuração e, como consequiência, para a homogeneidade do campo, através de seus aspectos coercitivos e regulativos.

DiMaggio e Powell (2001b) ainda informam que os campos existem à medida que estão definidos institucionalmente. Dessa maneira, as organizações passam por diversas formas. Porém, com o campo se estruturando, ocorre que as mesmas diminuem o seu grau de diversidade devido a pressões que acontecem no mesmo.

Fligstein (1997) ressalta a importância da estruturação dos campos abordando-o em relação à ação estratégica. Segundo o autor, quando o campo não tem estrutura, as possibilidades para a ação estratégica são maiores porque não há atores dominantes, fazendo com que eles se unam internamente e encontrem uma rede de acordos estáveis para o campo organizacional. Quando há a estruturação do campo, as regras são claras e os papéis dos atores são definidos, sendo aqueles que possuem uma maior relação de poder chamados de "incumbent" e os que exercem uma menor relação denominados "challenger".

O início da configuração de um campo consiste em organizações isoladas e distintas. Quando esse campo vai se estruturando, ocorre também uma maior interação, ocasionando uma homogeneidade entre as organizações que o compõem (HOLANDA, 2003). DiMaggio e Powell (2001b, p.106) informam que tanto o Estado quanto a profissionalização são os principais fatores que ocasionam essa similitude no campo organizacional.

[...] as organizações podem tratar de mudar constantemente; mas depois de certo ponto na estruturação de um campo organizacional, o efeito da mudança individual é reduzir o grau de diversidade dentro do campo. (DIMAGGIO; POWELL, 2001b, p.107)

Como dito anteriormente, as pressões ocorridas no campo fazem com que diminuam as formas organizacionais, ocorrendo uma maior homogeneização decorrente do isomorfismo. De acordo com Hawley (apud DIMAGGIO; POWELL, 2001b), o isomorfismo é um processo de pressão que força uma unidade em uma população a se parecer com outras unidades que se defrontam com o mesmo conjunto de condições ambientais. 
Esses processos de pressão podem ser classificados em competitivo - por enfatizar a competição do mercado e institucional - relacionado às políticas, mitos e cerimônias inseridas na vida das organizações.

No ambiente institucional existem três tipos de mecanismos isomórficos: o coercitivo, o mimético e o normativo. É importante salientar que a classificação desses mecanismos isomórficos é mais analítica, não sendo sempre possível separá-los empiricamente (DIMAGGIO; POWELL, 2001b), como evidencia o trabalho de Coser e Machado-da-Silva (2004) em um campo organizacional do município de Videira.

O mecanismo coercitivo se origina da influência política e do problema da legitimidade, consistindo de pressões tanto formais quanto informais que algumas organizações sofrem de outras das quais dependem para sobreviver (DIMAGGIO; POWELL, 2001b, p.109). Um exemplo pode ser o governo, que determina leis a serem cumpridas pelas organizações, ou uma grande organização, que impõe restrições às demais em suas transações (COSER; MACHADO-DA-SILVA, 2004).

O isomorfismo mimético resulta das respostas padronizadas às incertezas (DIMAGGIO; POWELL, 2001b, p.109). As organizações tendem a se modelar depois que organizações semelhantes em seu campo são percebidas como detentoras de legitimidade e bem-sucedidas. Um exemplo desse mecanismo é a obtenção de certificados de qualidade, como o ISO, por parte de algumas organizações (ROMANO; JUNQUILHO, 2004).

O terceiro tipo de isomorfismo, o normativo, deve-se principalmente à profissionalização, e nele os membros de uma categoria se esforçam e criam organizações reguladoras que estabelecem regras a serem seguidas por todos os profissionais daquela classe (DIMAGGIO; POWELL, 2001b, p.113). Um exemplo do isomorfismo normativo pode ser a Ordem dos Advogados do Brasil (OAB ), que define as atribuições desses profissionais, fazendo com que sejam reconhecidos por exercerem essa atividade, distinguindo-os dos profissionais de outras áreas como, por exemplo, dos médicos e dos professores. Essas profissões, entre tantas outras, já vêm imbuídas de significados que fazem com que as pessoas já saibam do que aquele profissional trata.

Machado-da-Silva e Fonseca (1996, p.103) ressaltam que a "tendência à homogeneização não anula as demandas competitivas". Segundo DiMaggio e Powell (2001b), isso ocorre porque as organizações não competem apenas por recursos e clientes, mas também por poder político, boa condição social e econômica, além de legitimidade institucional. Esses fatores também podem ocasionar mudanças isomórficas. Estas são previsíveis por existirem elementos nos níveis organizacionais e no campo capazes de identificarem-nas.

\section{Método}

Esta investigação consiste em uma pesquisa qualitativa, por ser a forma mais adequada de entender os aspectos subjetivos da influência de modelos de financiamento dos bancos no campo da cultura. Nesse caso, não se buscam variáveis apenas a fim de ver a influência de umas sobre as outras. O que se propõe aqui é compreender, em maior profundidade, o relacionamento entre bancos e organizações culturais, analisando discursos e ações e interpretando-os.

Os estudos que empregam uma metodologia qualitativa podem descrever a complexidade de determinado problema, analisar a interação de certas variáveis, compreender e classificar processos dinâmicos vividos por grupos sociais, contribuir no processo de mudança de determinado grupo e possibilitar, em maior nível de profundidade, o entendimento das particularidades do comportamento dos indivíduos. (RICHARDSON, 1985, p.39)

Dessa forma, será realizado um estudo de natureza exploratório-descritiva, pois além de aprofundar o estudo nos limites de uma realidade específica, descreverá sistematicamente um fenômeno de forma detalhada e objetiva (RICHARDSON, 1985; TRIVIÑOS, 1994; VERGARA, 1998), possibilitando um maior conhecimento a respeito do relacionamento entre bancos e organizações culturais. Assim, é possível conhecer um pouco melhor o que ocorre a partir dessas parcerias, se há uma influência na profissionalização do campo cultural, como também um enriquecimento desse setor através do apoio dado pelas instituições bancárias nas atividades realizadas por aquelas organizações. 
De acordo com Mazzotti e Gewandsnajder (1998, p.150), a pesquisa qualitativa geralmente se propõe a preencher lacunas no conhecimento existente e a verificar não apenas as inconsistências entre o que uma teoria prevê que aconteça e os resultados da pesquisa ou observações de práticas cotidianas, mas também as inconsistências entre resultados de diferentes pesquisas ou entre estes e o observado na prática.

Assim, de acordo com as características anteriormente explicitadas, pode-se perceber a adequação da abordagem qualitativa para a realização desta pesquisa, como também a utilização da teoria institucional para uma melhor análise e interpretação dos dados obtidos nesta investigação.

É importante ressaltar também que a amostra deste estudo é classificada como intencional ou de seleção racional porque os elementos que formam a amostra relacionam-se intencionalmente de acordo com certas características estabelecidas neste estudo, levando a uma maior compreensão do que acontece no campo cultural (RICHARDSON, 1985, p.107). De acordo com dados fornecidos pelo Banco Central do Brasil, no início de 2004 existiam instituições bancárias distintas atuando na cidade de Recife. Destas, apenas seis atuavam no campo cultural recifense, mas somente quatro casos serão apresentados, pois duas instituições representam um único caso e uma instituição não demonstrou interesse em participar deste estudo.

A coleta de dados foi feita através de consulta a documentos, jornais e à Internet, além de terem sido realizadas entrevistas semi-estruturadas com respondentes-chave das organizações estudadas. A análise dos dados ocorreu de forma documental e a do discurso dos entrevistas, à luz da teoria institucional.

\section{As instituições bancárias e suas ações culturais}

De acordo com a lista fornecida pelo Banco Central, verificamos que dos 24 bancos atuantes na cidade de Recife, apenas seis realizavam ações culturais. São eles: ABN AMRO Real Bank (Banco Real), Bandepe, Banco do Brasil, Banco do Nordeste, Caixa e Banco Itaú. Como dito anteriormente, embora existam seis instituições, há apenas quatro casos a serem analisados, visto que o Banco Real e o Bandepe realizam a mesma atividade cultural e que o Banco do Nordeste não mostrou interesse em participar da pesquisa.

A seguir serão mostrados os casos que foram estudados.

\section{Bandepe e ABN AMRO Real (Instituto Cultural Bandepe)}

O ABN AMRO Real Bank é fruto de várias aquisições de instituições financeiras. Em 1917 foi criado o banco Holandês Unido da América do Sul, que abriu a sua primeira filial em São Paulo no ano de 1945. Na década de 1960, incorporaram 100\% das ações da Aymoré Créditos, Financiamentos e Investimento. Em 1998 adquiriram os bancos Real e Bandepe e em 2003 chegou a vez do Sudameris fazer parte desta instituição. Atualmente, o ABN AMRO Real Bank é o quarto maior banco privado do país.

O Bandepe era um banco estadual que passou por várias mudanças desde sua privatização, o que faz com que algumas de suas atividades se confundam com as do banco que o comprou, visto que algumas diretrizes são traçadas para o grupo. Em maio de 2006, a marca Bandepe foi extinta e, em seu lugar, passou a ser utilizada apenas a marca do Banco Real (BANDEPE, 2006).

Os dois bancos anteriormente mencionados, juntamente com a Real Seguros, são os mantenedores do Instituto Cultural Bandepe. Esse instituto, antes da privatização do Bandepe, chamava-se Espaço Cultural Bandepe e foi construído para comemorar os 50 anos do banco. O Espaço Cultural era um local para exposições, lançamentos de livros, mostras e coquetéis (BANDEPE, 2004).

Quando o banco passou para o grupo ABN, o mesmo viu no Espaço Cultural uma forma de abrandar a calorosa polêmica que ocorreu devido à privatização da instituição bancária estadual. Esse espaço seria, então, uma "ação de marketing muito interessante e resolveu mantê-lo, não só mantê-lo, como ampliá-lo e reformá-lo e dotá-lo de recursos suficientes para que ele pudesse promover ações de cunho cultural dentro da cidade" (BRAGA, entrevista em 28-10-2004). 
Assim, o espaço cultural foi reformado e, um ano após sua inauguração, foi denominado Instituto Cultural Bandepe. $\mathrm{O}$ instituto atua da mesma forma que o antigo espaço cultural, valorizando a cultura pernambucana, de forma mais estruturada.

É importante salientar que as atividades culturais realizadas pelos bancos em Pernambuco ocorrem através desse instituto. "A gente prefere que as ações do instituto ocorram aqui dentro e as ações que ocorrem fora do Instituto sejam patrocinadas diretamente ou pelo Bandepe, ou pela Real Seguros ou pelo Banco Real" (TREVI, entrevista em 8-11-2004). É necessário ressaltar que essas ações são raras e que, geralmente, ocorrem em virtude de alguma possibilidade de negociação entre clientes em potencial.

Outro ponto que deve ser destacado é a atuação do instituto em relação a leis de incentivo. Há quatro anos que o Instituto Cultural Bandepe não utiliza as leis de incentivo para a realização dos seus projetos. O incentivo da Lei Rouanet, por exemplo, é utilizado para um projeto de grande porte que possa trazer maiores benefícios fiscais para o grupo.

Contudo, é necessário informar que as organizações são beneficiadas quando criam instituições culturais sem fins lucrativos, podendo vincular o nome da empresa patrocinadora à organização cultural, o que implica uma relação direta de imagem com a empresa e reconhecimento da sociedade (art. 27 da Lei Rouanet). Além desse fator, as instituições financeiras ainda são privilegiadas em relação às demais organizações, no que diz respeito aos benefícios tributários (MOISÉS, 2004, p.9).

Quanto à estrutura organizacional do Instituto Cultural Bandepe, é possível verificar que a mesma é muito enxuta, sendo composta apenas pelo seu coordenador e sua assistente. As demais pessoas que atuam no instituto são terceirizadas. Há um número fixo de pessoas que atuam no instituto realizando as atividades de segurança, limpeza e recepção, número que aumenta de acordo com a necessidade das exposições. Há também uma terceirização de monitores para a realização das mesmas, e estes recebem um treinamento sobre a exposição que esteja sendo apresentada naquele momento.

\section{Banco do Brasil e o Centro Cultural Banco do Brasil}

O Banco do Brasil (BB) atua desde 1808, na época colonial, e muitas mudanças ocorreram até chegar à estrutura que tem hoje. Sua atuação em Pernambuco iniciou em 1913. O BB é uma sociedade de economia mista e tem como principal acionista o governo federal brasileiro. Ele se destaca por financiar atividades desportivas e culturais. As atividades culturais desse banco ocorrem através dos centros culturais e do Circuito Cultural Banco do Brasil.

O primeiro Centro Cultural Banco do Brasil (CCBB) foi inaugurado em 12 de outubro de 1989, data de aniversário do Banco do Brasil, na cidade do Rio de Janeiro, e tinha o intuito de ser um pólo irradiador de cultura e um modelo de referência para o país. O objetivo com a criação desse CCBB era o de que ele atuasse como um shopping cultural realizando atividades em noves segmentos distintos: artes plásticas, cinema, vídeo, cursos e palestras, dança, música, museu e programa educativo.

Durante muito tempo, o objetivo do Banco do Brasil era ter apenas o CCBB no Rio de Janeiro, porém a sociedade começou a cobrar do banco que ele criasse outros centros culturais em outros estados. Assim, em 12 de outubro de 2000 era inaugurado o segundo CCBB, em Brasília, onde se localiza a sede do banco. E logo após, em abril de 2001, era a vez de ser inaugurado o CCBB de São Paulo. As pressões da sociedade fizeram com que o banco implantasse outros centros culturais, sendo um mecanismo de isomorfismo coercitivo porque são ações impostas pelo banco, além de ser um fator que contribuirá para compor o campo cultural.

Logo após a inauguração do Centro Cultural Banco do Brasil paulistano, iniciou-se uma busca do melhor local para implantar o quarto CCBB. O pré-requisito para a escolha era que o lugar estivesse situado nas regiões que ainda não possuíam um Centro Cultural Banco do Brasil. Depois de muitas pesquisas, a cidade de Recife foi escolhida para receber o próximo centro cultural. De acordo com Aragão e Alves (2002-2003, p.20) um dos principais motivos da escolha de Recife para abrigar o novo CCBB é o grande interesse da população local por 
atividades culturais. Esse interesse foi percebido pelo Banco do Brasil durante as edições do Circuito Cultural Banco do Brasil realizadas na cidade.

Além desse fator, a escolha de Recife para implantar o próximo CCBB decorre da sua importância mercadológica para o banco, além da sua localização privilegiada na região Nordeste e da sua relevância histórica para o país.

Pernambuco é um dos mercados mais importantes para nós, além de exercer um papel crescente no desenvolvimento e na integração do Nordeste. [...] além disso, a dinâmica da metrópole e seus projetos de revitalização consolidam a cidade para acolher novos negócios. (NAEGELE apud ARAGÃO; ALVES, 2002-2003, p.15)

A implantação do CCBB recifense seguirá os padrões dos outros CCBBs, o que pode revelar um isomorfismo coercitivo nas atividades culturais do Banco do Brasil. Entre as principais diferenças da implantação desse novo CCBB encontram-se o fato de que o prédio em que o CCBB será localizado não faz parte do patrimônio dessa instituição bancária. O Centro Cultural Banco do Brasil de Recife será instalado na antiga estação ferroviária de São José.

Para que o centro cultural fosse instalado nesse prédio foi necessário que o governo do estado de Pernambuco firmasse um convênio com a Rede Ferroviária Federal S.A (REFSA). Depois desse convênio, o governo do estado firmou um contrato de comodato com o Banco do Brasil, cedendo a antiga estação para abrigar o futuro CCBB, pois os CCBBs são instalados em prédios imponentes, históricos.

Outro fato que merece destaque é a localização do prédio, situado em local bastante movimentado, devido ao fluxo de usuários do metrô, o que proporciona visibilidade à marca do banco e atende a um dos seus principais objetivos que é a formação de platéia. A inauguração do CCBB Recife estava planejada para o ano de 2004, porém, por se tratar de um prédio que faz parte do patrimônio histórico da cidade, algumas alterações em seu projeto inicial tiveram que ser realizadas para atender aos requisitos da Fundação do Patrimônio Histórico e Artístico de Pernambuco (Fundarpe) (REBOUÇAS, 2004). Depois, o CCBB Recife teve a data de sua inauguração prorrogada para o final do ano de 2006. Porém, até o momento, o projeto não saiu do papel.

Antes da inauguração, o pessoal selecionado para trabalhar no novo CCBB será treinado pelos que já trabalham nos outros centros culturais. É importante salientar que os cargos de recepcionistas e de arte-educadores são selecionados juntamente com um responsável do CCBB. Esse zelo com a imagem do banco pode demonstrar a preocupação da instituição bancária em ser reconhecida pela sociedade em que atua, aumentando assim, a sua legitimidade.

O Circuito Cultural Banco do Brasil também surgiu da reivindicação das demais cidades que não possuíam CCBBs por atrações culturais desenvolvidas pelo Banco do Brasil. O Circuito Cultural foi uma fórmula encontrada pelo banco para realizar atividades culturais durante uma semana nas capitais brasileiras sem ser necessário implantar um centro cultural em cada estado do Brasil, que permitiria dar mais visibilidade à marca do banco em todo o país, visto que o mesmo tem grande atuação mercadológica no território nacional.

Diferente do CCBB, que recebe projetos de qualquer parte do mundo, o Circuito Cultural tem como objetivo a valorização da cultura local. Ele é formado por projetos inscritos, selecionados na região e por alguns projetos convidados. A partir do momento em que o CCBB Recife iniciar suas atividades, o projeto itinerante não será mais realizado nessa cidade, visto que a mesma irá possuir uma unidade permanente com atividades culturais.

\section{Itaú, Itaú Cultural e o Projeto Acervo Recordança}

No ano de 1945 iniciou-se a história do Banco Itaú Holding Financeira S.A., que é marcada por várias oportunidades de mercado, fazendo com que durante esses 60 anos muitas fusões nacionais e internacionais tenham sido realizadas. O Itaú, segundo maior banco privado do país, possui uma grande atuação, tanto nacional quanto internacional, estando presente em várias partes do mundo. 
A atuação do banco Itaú em atividades culturais ocorre por meio do Itaú Cultural. Essa instituição atua de duas formas: ora como centro cultural, ora como um instituto de pesquisas. Da primeira forma, atua disponibilizando uma programação diversificada, incluindo mostra de vídeos, shows, exposições de arte e encontros literários, entre outros, para a população, gratuitamente. Da segunda, através de pesquisas sobre várias segmentações artísticas, difundindo o trabalho realizado para várias instituições no país, através de catálogos, livros e CDs produzidos.

No âmbito da pesquisa, o Itaú Cultural realiza o programa Rumos, que visa mapear e integrar a produção cultural em todo o país, atuando nas seguintes áreas: cinema e vídeo, mídias interativas, pesquisa, jornalismo cultural, artes visuais, literatura, música e dança. Baseado em três objetivos - formação, fomento e difusão da classe artística brasileira -, o programa busca selecionar projetos inéditos ou já existentes, mas desconhecidos do grande público (ITAÚ CULTURAL, 2005).

É importante ressaltar que a maioria dos projetos do Itaú Cultural ocorre porque recebem apoio das leis de incentivo à cultura, seja no âmbito federal, estadual ou municipal, destacando-se a Lei Rouanet e a Lei Mendonça (cidade de São Paulo). Em 2005, o banco Itaú disponibilizou R $\$ 4,5$ milhões para a realização do programa (Itaú, 2005). Os demais recursos são provenientes das leis de incentivo. Outro aspecto que deve ser considerado é a vinculação da imagem da empresa à instituição cultural, permitida por lei, que garante mais visibilidade ao banco na sociedade. Além desse detalhe, é necessário enfatizar que o Itaú Cultural tem como hábito realizar apenas seus próprios projetos, ou seja, toda energia é direcionada para desenvolver os projetos que foram selecionados através do programa Rumos. Porém, toda regra tem sua exceção e é justamente a partir dessa ressalva que o Itaú Cultural atua em Recife, apoiando o Projeto Acervo Recordança.

O Projeto Acervo Recordança foi idealizado por Ana Valéria Vicente, presidente da Associação Reviva. Ela é dançarina e percebeu a carência de informações sobre os espetáculos realizados na cidade. Assim, surgiu o projeto que tinha como objetivo criar um banco de dados digital sobre os espetáculos de dança realizados em Recife nas décadas de 1970, 1980 e 1990, de forma que essas informações se tornassem mais acessíveis às pessoas interessadas.

Para concretizar esse projeto, a associação foi em busca de recursos, elaborando o projeto e enviando-o para vários locais que pudessem viabilizá-lo. A principal conquista pecuniária que receberam foi do Fundo Pernambucano de Incentivo à Cultura (Funcultura), onde o projeto foi aprovado. Mesmo antes de sair o resultado do Funcultura, as pessoas da Reviva continuavam buscando apoio para a realização do projeto. Um dos primeiros apoios que conseguiram foi da Fundação Joaquim Nabuco (Fundaj).

Além da Fundaj, a Reviva achou necessário que o Itaú Cultural ficasse ciente do projeto, por ser um das poucas instituições que atuam em dança no país, e pelo projeto ter uma relevância histórica e cultural que poderia contribuir para aumentar o conhecimento sobre esse segmento cultural.

O primeiro apoio do Itaú Cultural ao Acervo Recordança ocorreu em maio de 2003 e consistiu em uma consultoria com o objetivo de fazer um intercâmbio para formatar o projeto "de uma forma mais profissional, já utilizando o know-how que eles tinham" (VICENTE, entrevista em 28-1-2005).

A partir do êxito obtido com o projeto na cidade de Recife, a Fundaj começou a levar adiante a expansão dos projetos para o Nordeste e iniciou-se a busca de recursos para viabilizá-la.

Como o vínculo com o Itaú Cultural foi se estreitando, a partir da primeira fase do projeto tentou-se a possibilidade de co-realização com o instituto, por meio de uma verba que financiasse parte dessa expansão para o Nordeste. Todavia, existia um empecilho, o Itaú Cultural é conhecido por atuar só em seus projetos.

Mesmo não sendo habitual para o Itaú Cultural viabilizar projetos de terceiros, o Acervo Recordança, através da Fundaj, conseguiu, no final do ano de 2004, que o instituto disponibilizasse uma verba para estruturar a expansão do projeto nas cidades de Fortaleza e Salvador, que serão as primeiras a realizá-lo. A Fundaj, por ser uma instituição federal que já é legitimada, possui respaldo para obter mais recursos para o projeto Acervo Recordança, no momento em que este é sediado em suas instalações. 
Com essa necessidade de buscar parceiros para a viabilização do projeto, pode-se verificar uma parte da configuração do campo formada pelo projeto Acervo Recordança. Alguns atores organizacionais são a Fundaj, o Itaú Cultural, o governo do estado de Pernambuco e a Escola de Dança da Universidade Federal do Ceará (UFCE). Afora o projeto, a Associação Reviva ainda mantém vínculos com o Instituto Pensarte, o Instituto Histórico de Olinda e o Maracatu Estrela de Ouro de Aliança.

\section{Caixa Econômica Federal}

Fundada com o nome de Caixa Econômica e Monte de Socorre da Corte, a instituição foi criada com o objetivo de conceder empréstimos e incentivar a poupança, principalmente, das classes menos favorecidas (CAIXA, 2004), incluindo os escravos, os quais viam na instituição a possibilidade de conseguirem sua alforria.

Embora tenha passado por várias mudanças, a Caixa Econômica Federal continua atuando no desenvolvimento econômico e social do país. Todas as suas atividades decorrem das macrodiretrizes traçadas pelo governo. A sua atuação cultural também decorre dessas linhas traçadas amplamente, que vão se tornando realidade de acordo com a necessidade de cada região em que atua.

Atualmente, a Caixa investe em cultura na cidade de Recife através de patrocínios e parcerias com instituições públicas, em eventos que concentrem um grande número de participantes, trazendo visibilidade à marca e tendo como caráter social a geração de emprego e renda com essas ações. Uma das parcerias realizadas no ano passado foi o carnaval de Recife, juntamente com a Secretaria de Cultura da Cidade de Recife. É importante ressaltar que essas ações de patrocínios só são realizadas para pessoa jurídica. A única situação em que se disponibiliza verba para pessoa física é quando esta tem o seu projeto aprovado pela Lei Rouanet.

Em 2005 a Caixa não disponibilizou recursos para incentivo via Lei Rouanet devido à criação do programa Caixa de adoção de entidades culturais. Esse programa é de âmbito nacional, para entidades culturais, públicas ou privadas, sem fins lucrativos, que tenham a atuação cultural como atividade principal. É necessário salientar que a Lei $\mathrm{n}^{\circ}$ 9.874/99 permite abater $100 \%$ do percentual de imposto de renda devido nas modalidades de patrocínio e doação, beneficiando as pessoas físicas e jurídicas que realizam doação de acervos a museus.

Por ser uma organização estatal, uma das principais preocupações da Caixa ao patrocinar um evento é a dimensão social que o mesmo vai atingir, verificando se trará oportunidade de geração de emprego e renda para a população ou se é possível arrecadar alimentos para o programa social do governo federal Fome Zero.

Ao mesmo tempo em que há essa preocupação social em patrocinar eventos culturais, percebe-se também a oportunidade de mercado para veicular a marca da Caixa (requisito obrigatório quando se trata de patrocínio), assim como uma forma de estreitar o relacionamento da empresa com os seus clientes atuais e de aumentar a sua parcela de participação no mercado.

Outra forma de atuação cultural dessa instituição ocorre através do seu Conjunto Cultural, que são espaços onde a empresa promove, apóia e divulga as mais diversas manifestações artístico-culturais (CAIXA, 2004). Esses espaços estão localizados em Brasília, Curitiba, Salvador, Rio de Janeiro e São Paulo e são providos de teatros, galerias e museus. Brevemente, a capital de Pernambuco também será contemplada com um espaço cultural da Caixa.

Analisando os outros casos deste estudo, percebe-se que a forma como a Caixa atua no cenário cultural recifense é bastante distinta dos demais. Isso ocorre porque as suas ações são de patrocínio, enquanto as outras instituições financeiras possuem um espaço cultural responsável por suas ações na cidade. A Caixa possui os seus espaços culturais, mas nenhum deles atua ainda em Recife, fazendo com que não seja possível perceber uma maior colaboração para configurar o campo da cultura em Recife. 


\section{Considerações finais}

Neste artigo, constatamos que há duas formas pelas quais as instituições bancárias financiam cultura: diretamente, ou seja, quando a própria instituição bancária disponibiliza recursos para os investimentos culturais de terceiros, e indiretamente, atuando através de seus institutos culturais.

A partir dos dados coletados, podemos verificar que, no cenário cultural recifense, apenas dois bancos financiam cultura diretamente, são eles a Caixa Econômica Federal e o Banco do Nordeste. Vale ressaltar que ambos são instituições públicas. Porém, passam a estar moldadas, assim como toda a administração pública, às características predominantes da empresa privada. O modelo de financiamento direto ocorre através de patrocínios ou apoio a organizações culturais, através da própria instituição bancária que possui um departamento responsável por essas ações e que responde ao setor em um nível superior que se localiza na matriz da instituição. O Banco do Brasil, o Bandepe/Banco Real e o Banco Itaú financiam a cultura de forma indireta, ou seja, através de seus institutos ou centros culturais que são, respectivamente, o Centro Cultural Banco do Brasil, o Instituto Cultural Bandepe e o Instituto Itaú Cultural, que excepcionalmente investe em um projeto (Acervo Recordança) que não é seu.

Os modelos se distinguem, entre outros aspectos, pela sua forma de atuação. As instituições que utilizam seus espaços culturais acabam destinando suas atividades a um determinado público, que é aquele interessado nos projetos que estão sendo exibidos. Entretanto, o modelo de financiamento direto é mais voltado para ações desenvolvidas em locais de maior aglomeração e que atinjam várias classes sociais. Embora a maioria dos espaços culturais realize exposições, entre outros eventos, gratuitamente, os eventos patrocinados pelos bancos acabam sendo mais acessíveis por também terem como objetivo a geração de emprego e renda. Mais uma vez, independente da forma de atuação, é possível perceber a incorporação de uma lógica mercantil à escolha das manifestações culturais a serem financiadas.

A atuação cultural, como uma grande oportunidade de marketing para se legitimar, é outro ponto de semelhança verificado no discurso dos entrevistados. Regida por requisitos técnicos, a organização se vale de recursos que a possibilitem ser reconhecida pela sociedade na qual está inserida e, assim, consiga sobreviver.

Ao analisar o campo formado por essas organizações, encontram-se indícios de que a sua relação com atores que podem ser considerados reguladores, como, por exemplo, as secretarias de cultura, possui enlaces muito frágeis. Frágeis no sentido da regulação das suas atividades. No entanto, observamos que a maioria das instituições bancárias que investem no campo cultural recifense utiliza-se de dinheiro público, seja através das leis de incentivo à cultura ou por tratar-se de bancos públicos.

Assim, além de receberem isenção fiscal, ainda conseguem se promover, colocando suas marcas de patrocinadoras em todos os eventos e projetos que financiam. Não podemos esquecer que, apesar dessas instituições sofrerem pressões do ambiente para investirem em cultura, cabe ao Estado uma ação mais incisiva e reguladora. Afinal, os fracos enlaces percebidos entre os bancos, como atores que compõem uma parte do campo cultural recifense, e as secretarias e fundações de cultura tornam-se preocupante, corroborando as preocupações expostas no início do artigo. Dessa forma, o setor cultural passaria a ter que se submeter as regras impostas por organizações que não estão preocupadas com o lúdico ou com a preservação de manifestações artísticas, mas sim com o retorno financeiro que elas seriam capazes de oferecer.

Além disso, a preocupação presente ao se realizar tal pesquisa ocorreu ao perceber-se que, utilizando dinheiro, muitas vezes, público (como demonstrado anteriormente), as instituições bancárias têm investido em projetos primordialmente voltados para um grande público. A partir dos enlaces formados através das instituições bancárias e os atores que compõem o campo cultural, fica nítida uma escolha decisiva por projetos culturais voltados para um grande público. Não há preocupação em preservar a identidade da localidade, em desenvolver a cultura local. A ausência de uma ação reguladora do poder público só demonstra a força das instituições bancárias em utilizarem suas ações para promover espetáculos (e não cultura), com o objetivo de tornar sua marca fortalecida. 


\section{Referências}

ARAGÃO, Helena; ALVES, Rodrigo. CCBB Recife: ancoradouro da história, ponte para a cultura. Veredas, Rio de Janeiro, $2002-2003$. Especial Recife

BANCO CENTRAL DO BRASIL. Publicação eletrônica: agências PE-2004 [mensagem pessoal]. Mensagem recebida por <myrnaloreto@ig.com.br> em 26 abr. 2004.

BANCO DO BRASIL. Disponivel em: <http://www.bb.com.br/appbb/portal/hs/patrocinio/index.jsp>. Acesso em: 20 nov. 2004.

BANDEPE - Banco do Estado de Pernambuco. Disponivel em: <http://www.bandepe.com.br>. Acesso em: 24 out.2004.

BANDEPE. Novidades. Disponivel em:

<http://www.bandepe.com.br/bandepe/saiba_mais/principal.shtm?clique=Quadro\%20lnformativo_2006_04_07>. Acesso em: 20 abr. 2006.

CAIXA ECONÔMICA FEDERAL. Disponivel em: <http://www.caixa.gov.br>. Acesso em: 24 out.2004.

CARVALHO, Cristina A. P.; VIEIRA, Marcelo M. F.; LOPES, Fernando Dias. Contribuições da perspectiva institucional para a análise das organizações. In: ENCONTRO NACIONAL DE PÓS-GRADUAÇÃO EM ADMINISTRAÇÃO (ENANPAD), 22, 1998, Foz do Iguaçu (PR). Anais... CD-ROM.

Convergência estrutural e processual entre teatros e museus no Rio Grande do Sul. In: ENCONTRO NACIONAL DE PÓSGRADUAÇÃO EM ADMINISTRAÇÃO (Enanpad), 25., 2001, Campinas. Anais... CD-ROM.

COSER, Claudia; MACHADO-DA-SILVA, Clóvis L. Isomorfismo na rede de relacionamentos do Espaço Social de Videira - SC. In: ENCONTRO NACIONAL DE PÓS-GRADUAÇÃO EM ADMINISTRAÇÃO (Enanpad), 28., 2004, Curitiba. Anais... CD-ROM.

DIMAGGIO, Paul J. Construcción de un campo organizacional como un proyecto profesional: los museos de arte de los Estados Unidos (1920-1940). In: DIMAGGIO, Paul J; POWELL, Walter W. El nuevo institucionalismo en el análisis organizacional. México: Fondo de Cultura Económica, 2001

DIMAGGIO, Paul J.; POWELL, Walter W. Retorno a la jaula de hierro: el isomorfismo institucional y la racionalidad colectiva en los campos organizacionales. In: DIMAGGIO, Paul J; POWELL, Walter W. El nuevo institucionalismo en el análisis organizacional. México: Fondo de Cultura Económica, 2001a.

Introducción. In: El Nuevo institucionalismo en el análisis organizacional. México: Fondo de Cultura Económica, $2001 b$.

FLIGSTEIN, Neil. Social skill and institutional theory. American Behavioral Science, v.4, n.40, p.397-405, 1997.

HOLANDA, Luciana Araújo de. Formação e institucionalização do campo organizacional do turismo em Recife-PE. 2003. Dissertação (Mestrado em Administração) - Universidade Federal de Pernambuco, Recife, 2003.

ITAÚ abre inscrições para artes visuais e educação. Cultura e Mercado, 7 mar. 2005. Disponível em: <http://culturaemercado.terra.com.br/radar/noticias.php?id=677>. Acesso em 10 maio 2005.

ITAÚ CULTURAL. Disponivel em: <http://www.itaucultural.org.br>. Acesso em: 24 out. 2004.

JÓFILI, Rodrigo; DIAS, Thiago F; CARVALHO, Cristina A. P. Paixão de Cristo em Fazenda Nova: de referências locais a referências globais. In: CARVALHO, Cristina A. P; VIEIRA, Marcelo M. F. (Orgs.) Organizações, cultura e desenvolvimento local: a agenda de pesquisas do Observatório da Realidade Organizacional. Recife: EDUFEPE, 2003.

LEÃO Jr, Fernando Pontual de Souza et al. Administração de organizações culturais na nova ordem social: um estudo em museus e teatros das cidades de Recife e Porto Alegre. Organização e Sociedade, v.8, n.20, p.153-174, jan./abr. 2001.

LEÃO Jr, Fernando Pontual de Souza. et al. Administração de organizações culturais na nova ordem social: um estudo em museus e teatros das cidades de Recife e Porto Alegre. Organização e Sociedade, v.8, n.20, p.153-174, janeiro/abril, 2001.

LOPES, Fernando D. Teoria institucional e gestão universitária: uma análise do processo de avaliação institucional na UNIJUÍ. Revista Eletrônica de Administração. v.5, n.4, dezembro, 1999. Disponivel em:

<http://read.adm.ufrgs.br/read12/artigo/artigo4.htm>. Acesso em: 13 abr. 2004.

MACHADO-DA-SILVA, Clóvis L.; FONSECA, Valéria S. Competitividade organizacional: uma tentativa de reconstrução analítica. Organizações e Sociedade, v.4, n.8, p.97-114, dez. 1996. 
MADEIRO, Gustavo; CARVALHO, Cristina A. P. Da origem pagã às micaretas: a mercantilização do carnaval. In: CARVALHO, Cristina A. P.; VIEIRA, Marcelo M. F. (Org.). Organizações, cultura e desenvolvimento local: a agenda de pesquisas do Observatório da Realidade Organizacional. Recife: Edufepe, 2003.

MAGALHÃES FILHO, Paulo Azevedo de Oliveira. A configuração organizacional dos clubes de futebol do estado de Pernambuco e a expansão da lógica de mercado. Dissertação (Mestrado em Administração) - Universidade Federal de Pernambuco, Recife, 2003.

MAZZOTI, Alda Judith A.; GEWANDSNAJDER, Fernando. 0 método nas ciências naturais e sociais: pesquisa quantitativa e qualitativa. São Paulo: Pioneira, 1998.

MEYER, John; SCOT, Richard. Organizational environments: ritual and rationality. London: Sage, 1983.

MISOCZKY, Maria Ceci A. Campo de poder e ação em Bourdieu: implicações de seu uso em estudos organizacionais. In: ENCONTRO NACIONAL DE PÓS-GRADUAÇÃO EM ADMINISTRAÇÃO (Enanpad), 25., 2001, Campinas. Anais... CD-ROM.

MOISÉS, José Álvaro. Sobre o financiamento da cultura. Disponivel em <http://www9.cultura.gov.br/textos/ja15.htm>. Acesso em: 7 maio 2004.

PERROW, C. Sociología de las organizaciones. 3 ed. Madrid: McGraw-Hill, 1990.

REBOUÇAS, Julia. Filial local do CCBB só em 2005. Folha de Pernambuco, p.5 Recife, 13 out. 2004. Programa.

RICHARDSON, Roberto Jarry et al. Pesquisa social: métodos e técnicas. São Paulo: Atlas, 1985.

ROMANO, Bruno D.; JUNQUILHO, Gelson S. Reflexos do ISO 9000 e do PBOP-H na construção civil do Espírito Santo. In: ENCONTRO NACIONAL DE PÓS-GRADUAÇÃO EM ADMINISTRAÇÃO (Enanpad), 28., 2004, Curitiba. Anais... CD-ROM.

; VASCONCELLOS, João Gualberto M. Formação e estruturação do campo organizacional da construção civil do Espírito Santo. In: ENCONTRO NACIONAL DE PÓS-GRADUAÇÃO EM ADMINISTRAÇÃO (Enanpad), 27., 2003, Atibaia (SP). Anais... CD- ROM

; MEYER, John W. La organización de los sectores sociales: proposiciones y primeras evidencias. In: DIMAGGIO, Paul J.; POWELL, Walter W. El Nuevo institucionalismo en el análisis organizacional. México: Fondo de Cultura Económica, 2001.

TRIVIÑOS, Augusto N. S. Introdução à pesquisa em ciências sociais: a pesquisa qualitativa em educação. São Paulo: Atlas, 1994.

VERGARA, Sylvia Constant. Projetos e relatórios de pesquisa em administração. São Paulo: Atlas, 1998.

VIEIRA, Marcelo M. F; CARVALHO, Cristina A. Campos organizacionais: de wallpaper à construção histórica do contexto de organizações culturais em Porto Alegre e em Recife. In: Encontro Nacional de Pós-graduação em Administração (ENANPAD), 2003. Anais... CD-ROM

VIEIRA, Marcelo M. F; MISOCZKY, Maria Ceci A. Instituições e poder: explorando a possibilidade de transferências conceituais. In: CARVALHO, Cristina A. P; VIEIRA, Marcelo M. F. (Orgs.) Organizações, cultura e desenvolvimento local: a agenda de pesquisas do Observatório da Realidade Organizacional. Recife: EDUFEPE, 2003. 